\title{
Bile Acid Malabsorption in Cystic Fibrosis; Membrane Vesicles, a Tool for Revealing the Role of the lleal Brush Border Membrane
}

\author{
F. W. M. DE ROOIJ, J. W. O. VAN DEN BERG, M. SINAASAPPEL, ${ }^{1}$ \\ E. P. BOSMAN-JACOBS and A. C. TOUW-BLOMMESTEIJN \\ From the Department of Internal Medicine $I I$ and the ${ }^{1}$ Department of Pediatrics, subdivision Gastroenterology, \\ Erasmus University Rotterdam, 3000 DR Rotterdam, The Netherlands
}

\begin{abstract}
Rooij, F. W. M., van den Berg, J. W. O., Sinaasappel, M., ${ }^{1}$ BosmanJacobs, E. P. and Touw-Blommesteijn, A. C. (Department of Internal Medicine II and ${ }^{1}$ Department of Pediatrics, subdivision Gastroenterology, Erasmus University Rotterdam, 3000 DR Rotterdam, The Netherlands). Bile acid malabsorption in cystic fibrosis; membrane vesicles, a tool for revealing the role of the ileal brush border membrane. Acta Paediatr Scand Suppl 317.
\end{abstract}

Increased fecal bile acid loss in cystic fihrosis (CF) may result from ileal dysfunction. A method to quantitate in vitro $\mathrm{Na}^{+}$-dependent taurocholate uptake into brush border membrane vesicles prepared from frozen ileum and ileal biopsy specimen is described. This transport across the ileal brush border membrane can be measured selectively, in contrast to in vivo measurements which represent a complex overall process. Preliminary results obtained with ileal specimen of 2 CF patients, suggest that in vitro bile acid uptake is low but not abnormal. Key words: Bile acids, brush border membrane, cystic fibrosis, ileal transport.

Increased fecal bile acid loss is found in a variety of gastrointestinal diseases and bile acid malabsorption may result from ileal dysfunction. In cystic fibrosis (CF) increased fecal bile acid loss is also one of the phenomena (1); furthermore a decreased bile acid pool is found in CF (2). Fondacaro et al. (3) suggested that reduced bile acid absorption in the terminal ileum of CF patients may cause bile acid loss in CF. Although bile acids are absorbed by passive diffusion, most important is the $\mathrm{Na}^{+}$-dependent active absorption of conjugated bile acids (against a concentration gradient) in the terminal ileum. The more viscous mucus layer, as found in CF, may be a factor in diminished bile acid absorption as well. We have been able to characterize the ileal $\mathrm{Na}^{+}$-dependent taurocholate transport across the brush border membrane in vitro by preparing brush border membrane vesicles (BBMV) from microquantities (25-200 mg) of ileum, allowing the use of biopsy specimen (4). BBMV were prepared according to an adaptation of the method of Kessler et al. (5). Vesicles, prepared in this way from enterocyte brush border membranes, do have the "right side out» configuration. The outer side of those BBMV normally is exposed to the luminal content. The absorptive capacity of the ileal enterocytes for specific components like bile acids can be studied in vitro, separated from the complex in vivo situation. In this study uptake of ${ }^{3} \mathrm{H}$-taurocholate into the $\mathrm{BBMV}$ in the presence of a $100 \mathrm{mM} \mathrm{NaCl}$ gradient is followed during $1 \mathrm{~min}$. Samples were taken at 20, 40 and $60 \mathrm{sec}$ after starting the incubation and uptake was related to the amount of membrane protein.

\section{MATERIALS AND METHODS}

Brush border membrane vesicle isolation

Brush border membrane vesicles (BBMV) were prepared (at $0-4^{\circ} \mathrm{C}$ ) according to an adaptation of the procedure of Kessler et al. (5), based on a precipitation with divalent cations. Frozen $\left(-70^{\circ} \mathrm{C}\right)$ ileal specimen $(25-200 \mathrm{mg})$ obtained after resection, obduction or as endoscopical biopsy were thawed in isotonic buffer $(300 \mathrm{mM}$ mannitol, $12 \mathrm{mM}$ Tris- $\mathrm{HCl}, \mathrm{pH} \mathrm{7.1)}$ at a final concentration up to $250 \mathrm{mg} / \mathrm{ml}$. Disruption of the material was carried out in an "Eppendorf" tube in a minimal buffer volume of 150 


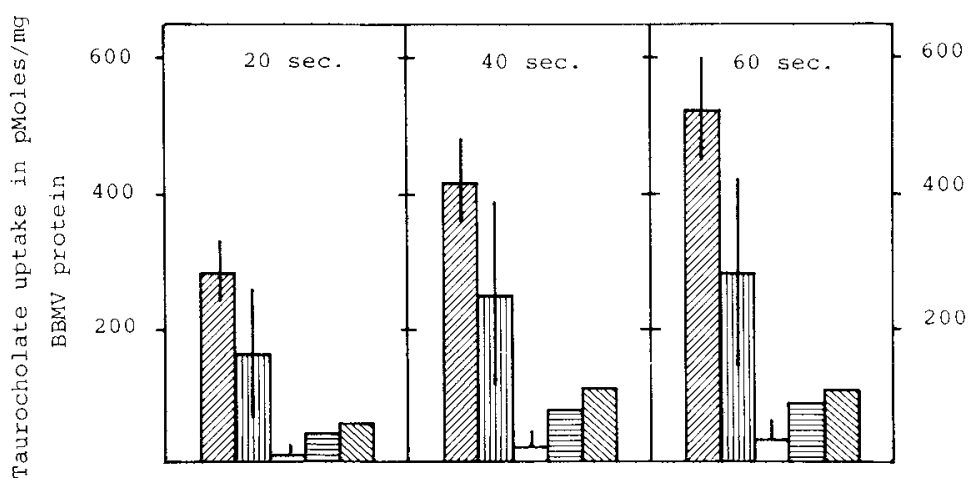

Q2eference, rabbit ileum $(n=6)$, 血 normal human ileum $(n=52)$

$\square$ ileitis $(n=5)$, and $\mathrm{CF}$ ileum $(n=2)$

Fig. 1. Taurocholate uptake into brush border membrane vesicles (BBMV). BBMV were prepared from microquantities of rabbit ileal segments of from colonoscopical biopsy specimen, histologically diagnosed as normal ileum or ileitis, and from two surgical specimen from CF patients. The standard deviation is indicated.

$\mu l$ for two $45 \mathrm{sec}$ periods using a Vibro-mixer (Model E1 from Chem. Ap. A. G. Mannedorf Z.H., Switzerland) fitted with a glass rod. If present, the suspension was cleared from small pieces of muscle and connective tissue using a microliter pipette. Then, the suspension was diluted with 5 volumes of icecold water and $\mathrm{MgCl}_{2}$ was added to a final concentration of $10 \mathrm{mM}$. After 40 min the suspension was centrifuged at $3000 \times \mathrm{g}$ for $15 \mathrm{~min}$. The supernatant was decanted into another tube and stored at $0^{\circ} \mathrm{C}$. The pellet was resuspended in buffer $(50 \mathrm{mM}$ mannitol, $2 \mathrm{mM}$ Tris- $\mathrm{HCl}, 10 \mathrm{mM}$ $\mathrm{MgCl}_{2}, \mathrm{pH} 7.1$ ) and after $40 \mathrm{~min}$ this suspension was centrifuged as before. The pellet was discarded. The two supernatant fractions were combined and centrifuged for $30 \mathrm{~min}$ at $27000 \times \mathrm{g}$ to spin down the BBMV. The final BBMV pellet was resuspended in $34 \mu$ l buffer ( $100 \mathrm{mM}$ mannitol, $1 \mathrm{mM}$ HEPESTris, $10 \mu \mathrm{M} \mathrm{MgSO}$, pH 7.5) using a "Hamilton" syringe. Protein content was determined in duplicate on $6 \mu \mathrm{l}$ samples (6).

\section{Transport measurements}

The BBMV suspension $(17 \mu \mathrm{l})$ was preincubated for $5 \mathrm{~min}$ at $25^{\circ} \mathrm{C}$ and the incubation was started by addition of $204 \mu \mathrm{l}$ of transport buffer $(100 \mathrm{mM}$ mannitol, $108 \mathrm{mM} \mathrm{NaCl}, 1 \mathrm{mM}$ HEPES-Tris, $10 \mu \mathrm{M}$ $\left.\mathrm{MgSO}_{4}, \mathrm{pH} 7.5\right)$ containing $4 \mu \mathrm{M}{ }^{3} \mathrm{H}$-taurocholate $(6.6 \mathrm{Ci} / \mathrm{mmol}$ New England Nuclear Corp.). Samples $(50 \mu \mathrm{l})$ of the incubation mixture were taken at selected times $(20,40$ and $60 \mathrm{sec})$ and diluted in $4 \mathrm{ml}$ icecold stop buffer $(100 \mathrm{mM}$ mannitol, $100 \mathrm{mM} \mathrm{NaCl}, 1 \mathrm{mM}$ HEPES-Tris, $10 \mu \mathrm{M} \mathrm{MgSO}$, $\mathrm{pH}$ 7.5 saturated with lithocholate $(\leqslant 50 \mu \mathrm{M})$ ), filtered over a membrane filter (Sartorius SM 11306, 0.45 $\mu \mathrm{M}$ pore size) on a filtration unit (Amicon Manifold, pressure difference $650-700 \mathrm{mmHg}$ ) and washed 4 times with $4 \mathrm{ml}$ of the same stop buffer. Each membrane filter was dissolved in $10 \mathrm{ml}$ scintillation liquid. Radioactivity was measured in a liquid scintillation counter.

\section{RESULTS}

The microprocedure was validated on both fresh frozen rabbit ileum and human obduction ileum (4). Uptake determinations were performed with colonoscopical ileal biopsy specimen histologically diagnosed as normal $(n=52)$ and ileitis $(n=5)$, as well as with ileal specimen of two CF patients. The CF specimen were taken from the resection area during the closure of an ileostomy. We used frozen rabbit ileum as a reference for our in vitro assay (see Fig. 1).

\section{DISCUSSION}

Increased fecal bile acid loss in CF may be due to a reduced or absent active ileal transport (3). The brush border membrane plays a major role in the $\mathrm{Na}^{+}$-dependent active bile acid 
transport of the ileum. Therefore we studied the integrity of this process in two CF patients. The assay described here has already shown its diagnostic value for patients with increased fecal bile loss of unknown origin. In five patients with histologically proven ileitis and with increased fecal bile acid loss, a decreased in vitro taurocholate uptake was found. The uptake measured in this assay represents only the active bile acid uptake capacity of brush border membranes. Altered viscosity of mucus, as found in CF, does not affect our results because no mucus layer is present on the BBMV. Moreover, due to the low bile acid concentration used in the assay, the uptake is not disturbed by a contribution of the passive diffusion of bile acids. Preliminary results obtained with ileal specimen of 2 CF patients suggest that in vitro bile acid uptake is low but not abnormal.

\section{REFERENCES}

1. Weber AM, Roy CC, Morin CL, Lasalle R. Malabsorption of bile acids in children with cystic fibrosis. N Engl J Med 1973; 289: 1001-05.

2. Watkins JB, Tercyak AM, Szczepanik P, Klein PD. Bile salt kinetics in cystic fibrosis (CF): Influence of pancreatic enzyme replacement. Gastroenterology 1977; 73: 1023-28.

3. Fondacaro JD, Heubi JE, Kellog FW. Intestinal bile acid malabsorption in cystic fibrosis: A primary mucosal cell defect. Pedidatr Res 1982; 16:494-98.

4. de Rooij FWM, van den Berg JWO, Bosman-Jacobs EP, Touw-Blommesteijn AC. Taurocholate uptake in brush border membrane vesicles from rat, rabbit and human ileum. Gastroenterol Clin Biol 1983; 7:511.

5. Kessler M, Acuto O, Storelli C, Murer H, Muller M, Semenza G. Transporting vesicles from small intestinal brush border membranes. Biochim Biophys Acta 1978; 506: 136-54.

6. Lowry OH, Rosebrough MJ, Lewis Farr A, Randall RJ. Protein measurement with the Folin Phenol Reagent. J Biol Chem 1951; 193: 265-74.

(FWM de R) Department of Internal Medicine II

P.O.B. 1738

Erasmus University Rotterdam

3000 DR Rotterdam, The Netherlands 